\title{
FINE NEEDLE ASPIRATION CYTOLOGY AS A DIAGNOSTIC TOOL; AN ASSESSMENT
}

Do Thi Trang ${ }^{1}$, Duong Thi Dung ${ }^{2}$, Tran Thi Minh Thu ${ }^{3}$

${ }^{1}$ Hanoi Medical University, Hanoi, Vietnam

${ }^{2}$ Hanoi Medical University, Hanoi, Vietnam

${ }^{3}$ School of Medicine \& Pharmacy, Vietnam National University, Vietnam

*Corresponding Author: Do Thi Thang

Article Received: 10-06-19
Accepted: 28-09-19
Published: 05-10-19

Licensing Details: Author retains the right of this article. The article is distributed under the terms of the $\begin{array}{lllll}\text { Creative } & \text { Commons } & \text { Attribution-NonCommercial } & 4.0 & \text { License }\end{array}$ (http://www.creativecommons.org/licences/by-nc/4.0/) which permits non-commercial use, reproduction and distribution of the work without further permission provided the original work is attributed as specified on the Journal open access page

\begin{abstract}
The study is about breast lesions which is a common cause of mortality and morbidity among females. To avoid negative consequences, there is need for urgent diagnosis and treatment. Fine Needle Aspiration Cytology (FNAC) is a useful diagnostic tool and possess higher level of accuracy. In this study, the objective was to determine the accuracy of FNAC in diagnosis of palpable breast lumps. Additionally, the objective was to find the correlation between cytological findings and histopathological examination of surgical specimens. The methodology of the study was based on retrospective study method. FNAC of breast lump was conducted on 271 patients out of which 104 formed the base group. The results showed that there were 104 patients of base study who had average age of 32 years. There were 54 patients with lump in left breasts, and 46 patients with lump in right breasts and 4 patient had bilateral lump. There were 77 patients with benign, 34 patients with malignant, and 3 had atypica;/suspicious lesions on cytological examination. Based on histopathological examination, 77 cases were related to benign, 26 were related to malignant, and 1 with atypical/suspicious. Cyto-histological concurrence was $93.05 \%$ and $79.2 \%$ for Fibroadenoma and Infiltrating ductal carcinoma respectively. Overall sensitivity of FNAC procedure was $94.17 \%$, specificity $100 \%$ and accuracy $93.26 \%$. On the basis of result,
\end{abstract}


it is concluded that FNAC is a simple, reliable method for diagnosis of both benign and malignant lesions and can be used in the evaluation of breast lesions.

Keywords: Cytology, Fine Needle, Women, Cancer.

\section{INTRODUCTION}

A lot of women suffer because of lesions of the breasts. Carcinoma of breast is a common female breast cancer across the world. During recent years, the incident of women suffering from carcinoma breast is increasing creating an emergency situation [1]. This diseases require timely diagnosis and prompt treatment in order to avoid fatality. One method of early diagnosis of breast lesions is Fine Needle Aspiration Cytology (FNAC). The benefit of this technology is that it can diagnose accurately, rapidly, and with minimum cost and no morbidity to patients. The procedure is simple and can be performed in even outpatient departments. It remains part of 'triple approach' which is about clinically examination of breasts and mammography and/or ultrasonography findings besides the FNAC. It is a multidisciplinary approach and used for preoperative assessment of breast lesions and make decision regarding the most suitable treatment of the patient $[2,3]$. In current study, we further explore the FNAC. Our specific objectives are as follows;

- To test the accuracy of FNAC in diagnosis of palpable breast lumps.

- To correlate the cytological findings with histopathological examination of surgical biopsy, lumpectomy or mastectomy specimens.

\section{MATERIALS AND METHODS}

Based on methodology, the present study is retrospective and conducted in pathology department of a public hospital in Vietnam. The duration of the study is 2 years. Total of 271 patients participated in procedure related to FNAC who visited the outpatient department of the hospital and had problems of palpable breast lump. $10 \mathrm{ml}$ disposable syringe and $23 \mathrm{G}$ disposable needle was used for conducting the aspiration. The smears were wet-fixed in $95 \%$ ethyl alcohol and stained with Haematoxylin and Eosin (H\&E) stain. 104 patients underwent tru-cut biopsy, lumpectomy or mastectomy. All surgical specimens were processed by routine histotechnical procedure and stained by $\mathrm{H} \& \mathrm{E}$. the process was only conducted on female and patients who underwent FNAC without subsequent histopathological examination, patients with inadequate biopsy, and patients with inconclusive cytology were excluded.

\section{RESULTS}

We performed FNAC of breast lump on 271 selected patients who were presented to the outpatient department. Out of these patients, 104 patients which is equal to $38.4 \%$ undergone subsequent bipsy, mastectomy or lumpectomy. We used these 104 cases as study group for cytohistopathological correlation of various lesions of breasts. Some patients were lost while other were referred to higher centers for further management. 


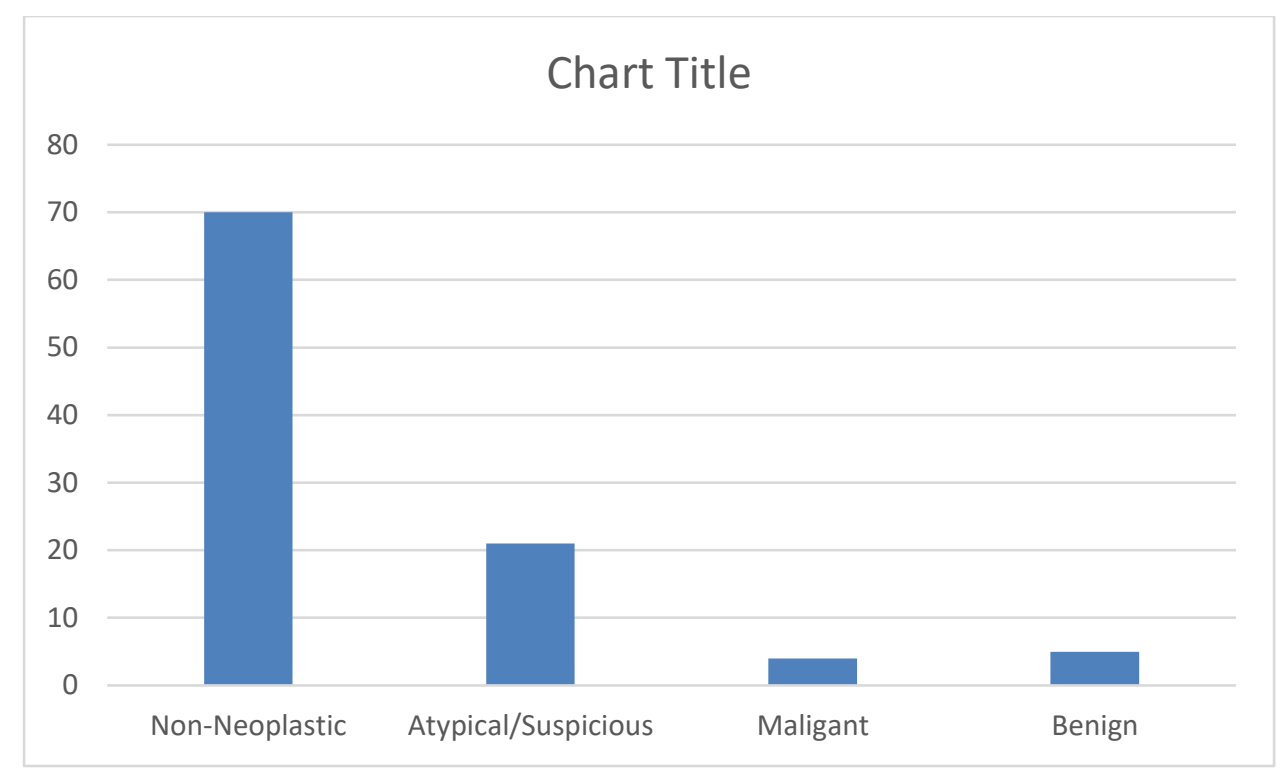

Figure 1:Sector diagram for cytology cases.

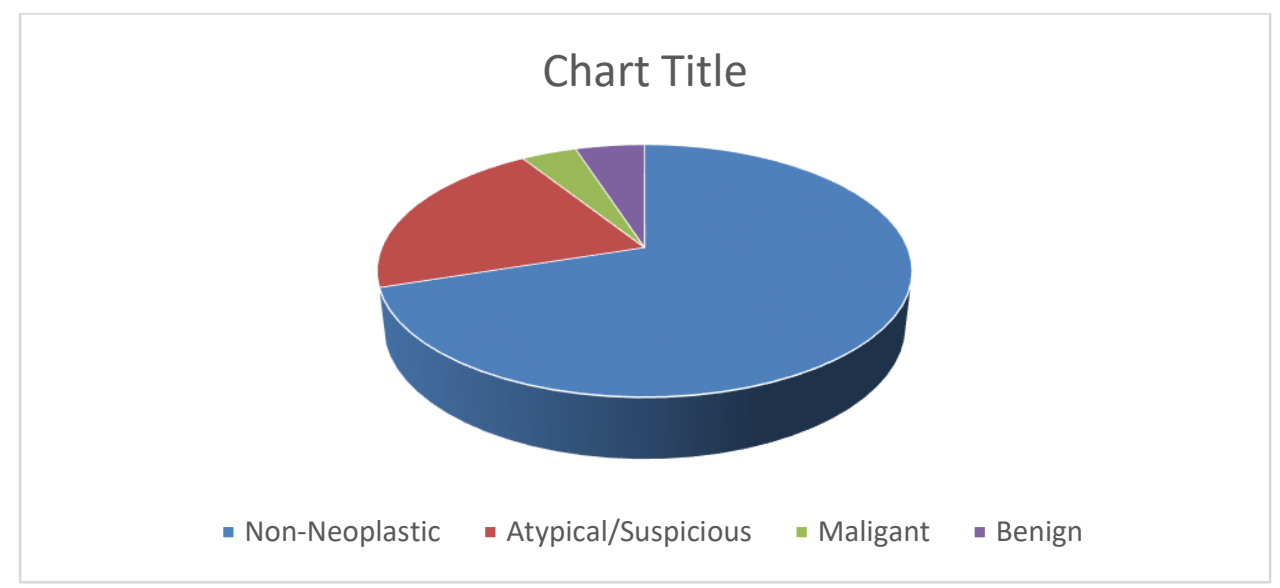

Figure 2: Pie diagram for distribution of Histology cases.

The age range was 14 years to 70 years. The average age was 32 years. The youngest patient (14 years) was diagnosed as fibroadenoma and the oldest patient (70 years) was positive for malignancy on cytology. There were 54 patients who had lump in their left breast while, 46 patient had lump in their right breast; while, 4 patients had bilateral lumps.

Table 1: Cytological Diagnosis of Breast Lesions (104 Cases).

\begin{tabular}{|l|l|l|l|}
\hline Category & Diagnosis & Number of cases & Percentage \\
& & & $(\%)$ \\
\hline \multirow{2}{*}{ Benign (Neoplastic and Nonneoplastic) } & Fibroadenoma & 71 & 68.26 \\
\cline { 2 - 4 } & Fibrocystic ds. & 3 & \\
\cline { 2 - 4 } & &
\end{tabular}




\begin{tabular}{|l|l|l|l|}
\cline { 2 - 3 } & \multicolumn{1}{|l|}{$\begin{array}{l}\text { Granulomatous } \\
\text { mastitis }\end{array}$} & 1 & \multirow{2}{*}{5.76} \\
\cline { 2 - 3 } & Cyst & 2 & \\
\hline Atypical / Suspicious & 4 & 3.84 \\
\hline Malignant & 23 & 22.11 \\
\hline
\end{tabular}

On cytology, 71 cases were fibroadenoma, 3 cases were related to malignancy. In terms of histopathology, fibroadenoma was the highest category based on 71 cases, followed by infiltrating duct carcinoma which was based on 23 cases. The following table presents the cytohistopathological of the breast lesions. 2 cases each of granulomatous mastitis and fibrocystic disease on cytology were confirmed on histopathology (Figure IIIa \&IIIb \& IV).

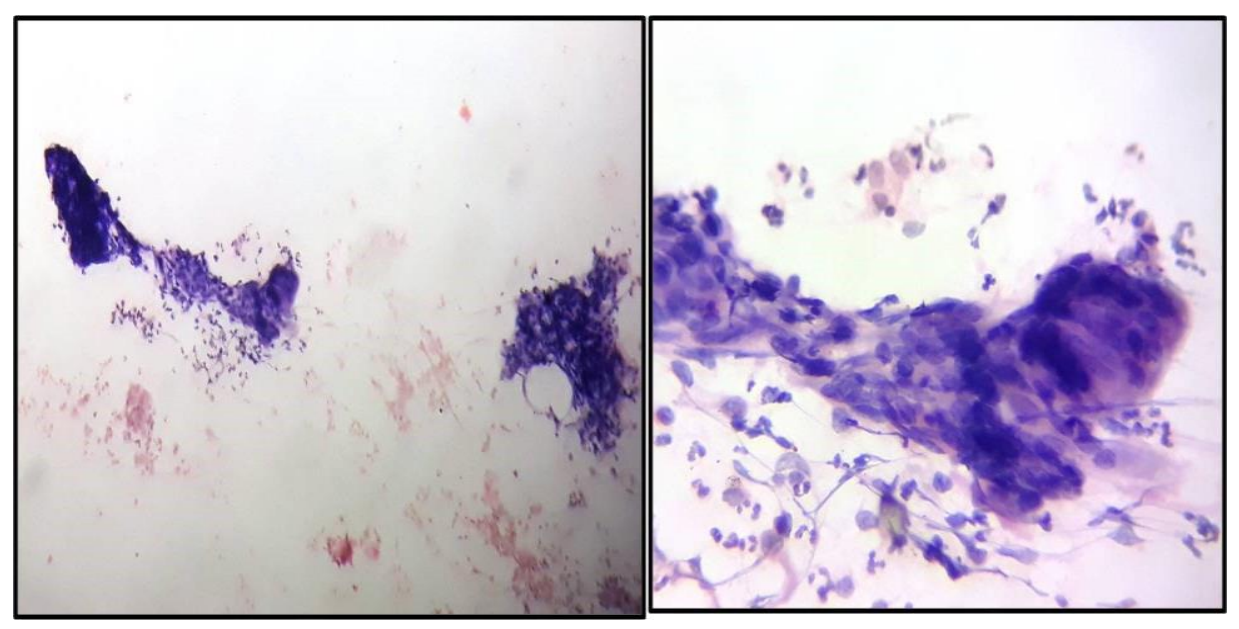

Figure 3a: Granulomatous Mastitis (Cyto: $H \&$ E $10 X \& 40 X)$.
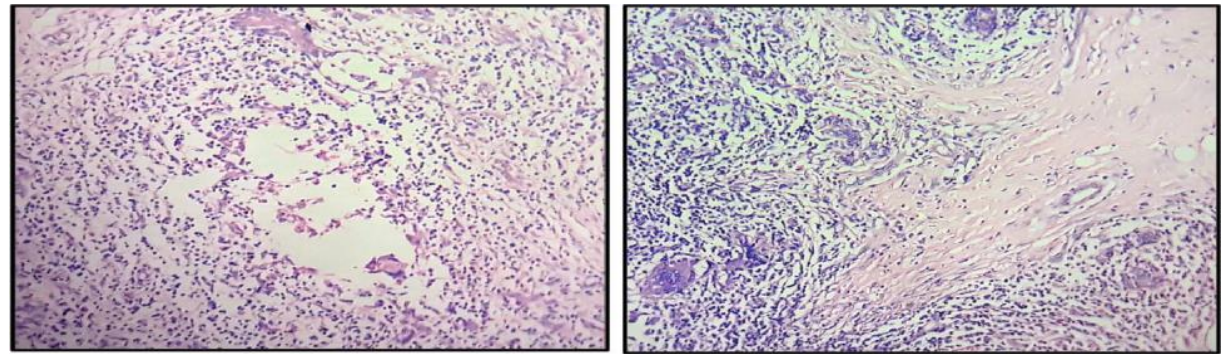

Figure 3b: Granulomatous Mastitis (Histo: $H \& E 4 X \& 10 X)$. 

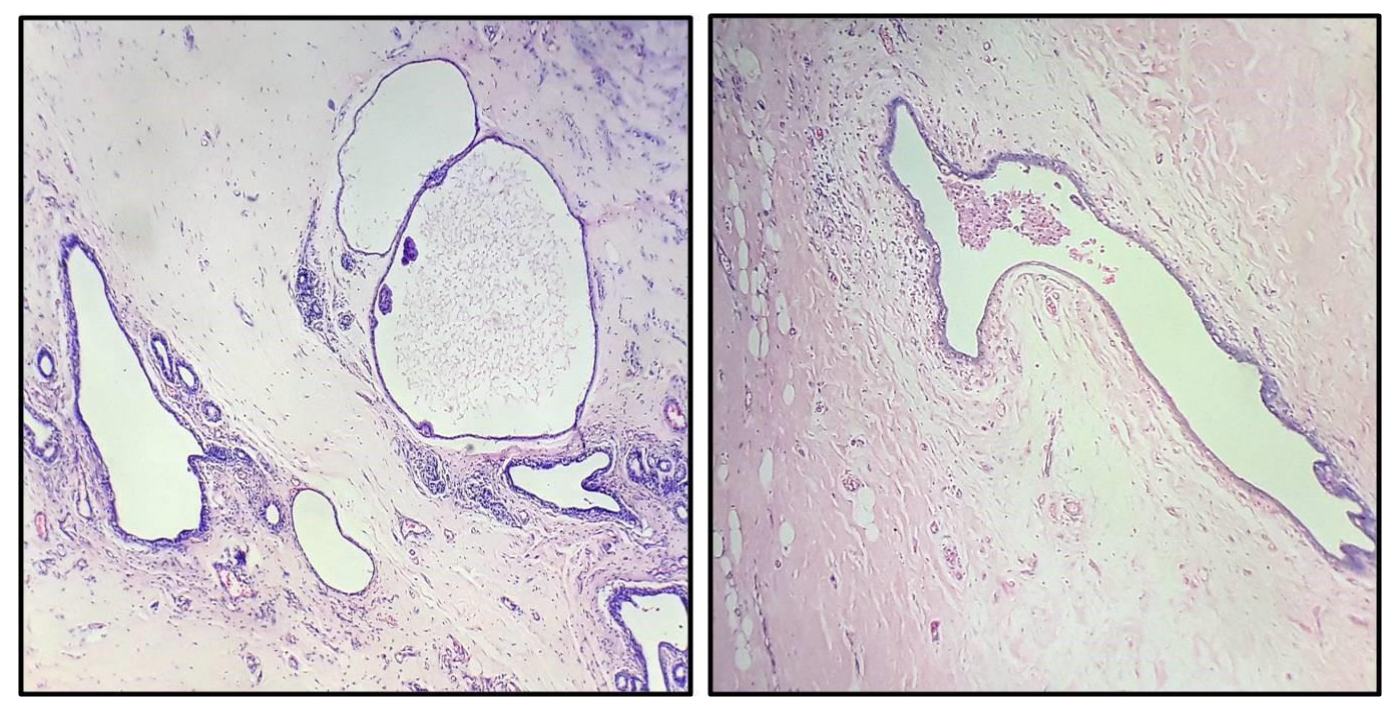

Figure 4: Fibrocystic disease (Histo: $H \& E 4 X \& 10 X)$.

Table 2: Histopathological diagnosis of breast lesions (104 cases).

\begin{tabular}{|c|c|c|c|}
\hline Category & Diagnosis & $\begin{array}{l}\text { Number of } \\
\text { cases }\end{array}$ & $\begin{array}{l}\text { Percentage } \\
(\%)\end{array}$ \\
\hline \multirow[t]{2}{*}{ Benign } & Fibroadenoma & 66 & \\
\hline & Phyllodes tumour & 02 & \multirow[b]{2}{*}{66.57} \\
\hline \multirow[t]{4}{*}{$\begin{array}{l}\text { (Neoplastic } \\
\text { Nonneoplastic) }\end{array}$} & Intraductal papilloma & 02 & \\
\hline & Fibrocystic ds. & 01 & \multirow[b]{3}{*}{07} \\
\hline & Granulomatous mastitis & 03 & \\
\hline & Duct ectasia & 01 & \\
\hline Atypical / Suspicious & Fibroadenoma with atypical ductal hyperplasia & 02 & 01 \\
\hline \multirow[t]{4}{*}{ Malignant } & $\begin{array}{l}\text { Infiltrating ductal carcinoma, Not otherwise specified } \\
\text { (IDC, NOS) }\end{array}$ & 21 & \multirow[b]{4}{*}{24} \\
\hline & Infiltrating lobular carcinoma & 04 & \\
\hline & Mucinous carcinoma & 02 & \\
\hline & Mixed IDC \& ILC & 02 & \\
\hline
\end{tabular}

Out of 72 cases of fibroadenoma, 66 were confirmed on histopathology, 2 case showed atypical ductal hyperplasia on histopathology, 2 were reported as phyllodes tumor and 1 each as intraductal papilloma and duct ectasia. 
Out of the 3 cases with atypical/ suspicious features on cytology, 1 was diagnosed as fibroadenoma on histopathology. 2 other cases were infiltrating ductal carcinoma and mucinous carcinoma respectively (Figure V).

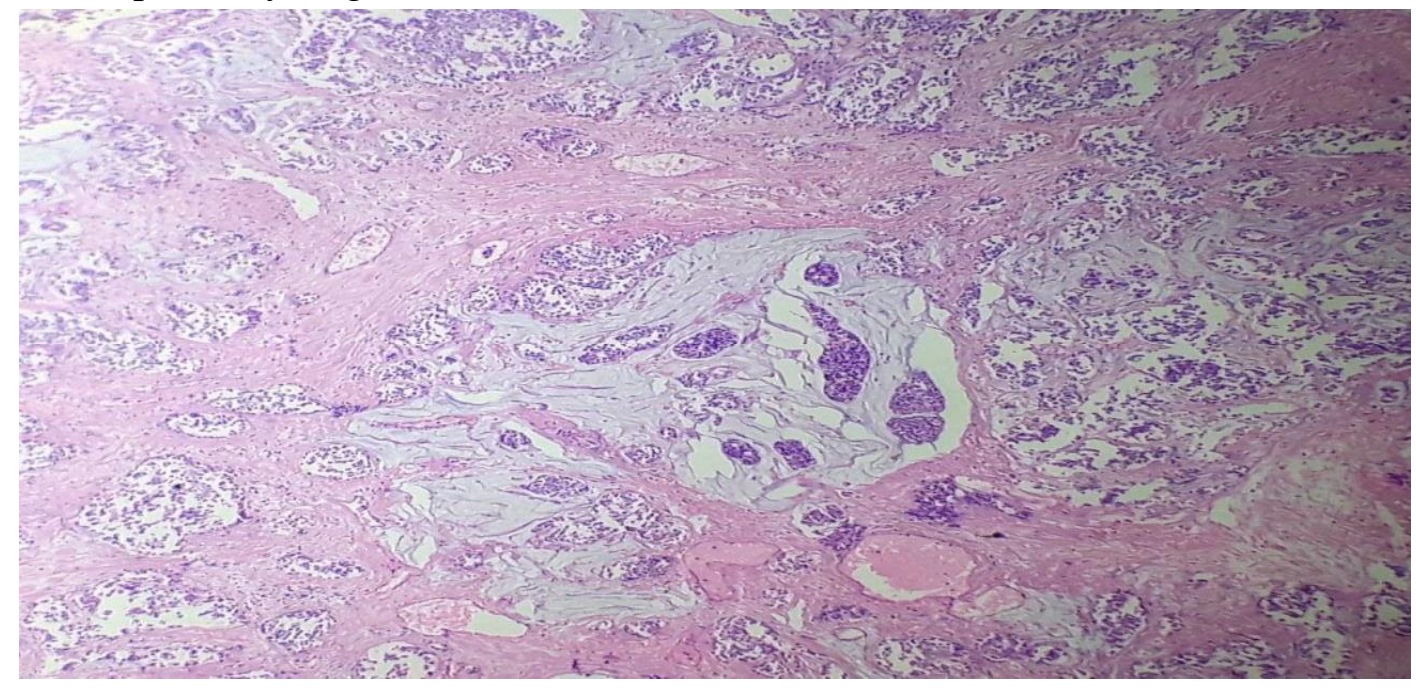

Figure 5: Mucinous carcinoma (Histo: $H \& E 4 X$ ).

All 24 cases of malignancy on cytology were confirmed as malignant on histopathology.

\section{Discussion}

Breast lesions including carcinoma of breast most commonly present with a clinically palpable breast mass. Fine Needle Aspiration Cytology was used by Martin and Ellis and Stewart in 1930 for the diagnosis of palpable breast lesions. Since that time, the method is used as valuable diagnostic tool for evaluation of breast lesions [4]

Table 3: Cyto-histological correlation (104 cases)

\begin{tabular}{|c|c|c|c|c|c|c|c|c|}
\hline & \multicolumn{8}{|c|}{ CYTOLOGICAL DIAGNOSIS } \\
\hline & & FA & $\begin{array}{l}\text { Fibrocy- } \\
\text { stic } \\
\text { disease }\end{array}$ & $\begin{array}{l}\text { Granulom- } \\
\text { atous mastitis }\end{array}$ & Cyst & $\begin{array}{l}\text { Atypical/ } \\
\text { suspicious }\end{array}$ & Malignant & $\begin{array}{l}\text { Number } \\
\text { of cases } \\
(\mathrm{HP})\end{array}$ \\
\hline \multirow[b]{2}{*}{$\begin{array}{l}\mathbf{H} \\
\mathbf{I} \\
\mathbf{S} \\
\mathbf{T} \\
\mathbf{O} \\
\mathbf{L}\end{array}$} & FA & 67 & - & - & - & 01 & - & 68 \\
\hline & Phyllodes tumour & 02 & - & - & - & - & - & 02 \\
\hline
\end{tabular}




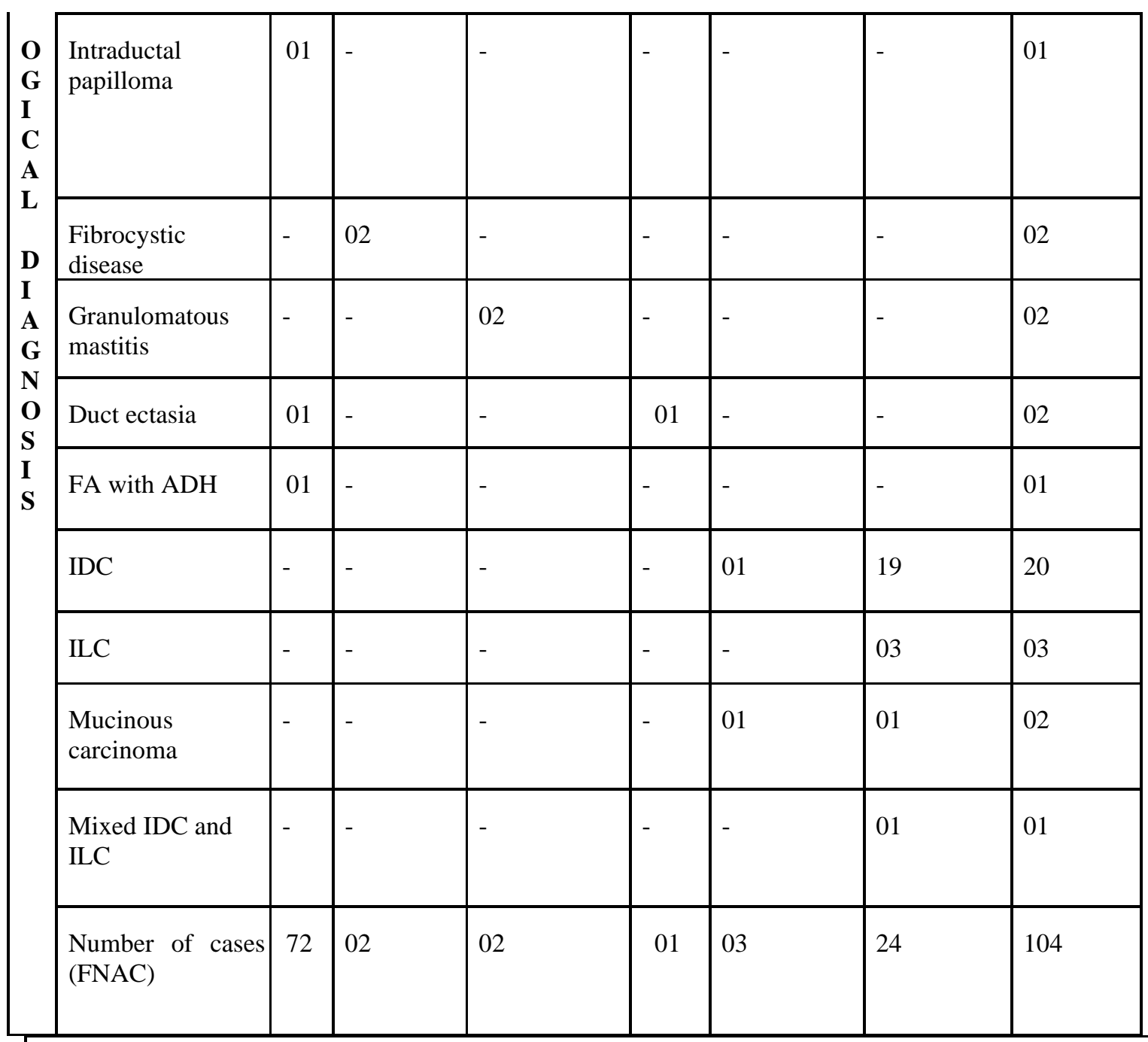

FA: Fibroadenoma, ADH: Atypical ductal hyperplasia, IDC: Infiltrating ductal carcinoma, ILC: Infiltrating lobular carcinoma, FNAC: Fine needle aspiration cytology, HP:

Histopathology.

In the present study, FNAC of breast lump was performed in 271 patients, out of which 104 cases underwent histopathological investigation and were considered as our study group. The incidence of benign lesions was more in 2 nd to 4 th decades of life while malignant lesions were seen in 4 th to 7 th decades.

In the present study, 54 cases (51.9\%) presented with lump in left breast, 46 cases (44.2\%) with lump in right breast and 4 cases (3.8\%) presented with bilateral breast involvement. Hussain MT have reported left and right breast involvement in 54\% cases and $46 \%$ cases respectively, in their study. ${ }^{6}$ In a study by Sushma Yalavarthi et al, most lesions were in left breast, 52.22\%. ${ }^{7}$ Thus our findings are matching with other studies which also reported higher incidents of left breasts cases compare to the right one.

In our study, on cytology, out of 104 cases, 72 cases (69\%) were fibroadenoma, 24 cases (23\%) were malignant, 5 cases $(5 \%)$ were non-neoplastic and 3 cases $(3 \%)$ were atypical/ suspicious 
lesions. In the study by Varsha Pandey benign lesions were $70.5 \%$, malignant lesions were $27.9 \%$ and inflammatory $8.65 \%$.[5, 6, 7] In study by Khanna, $61.3 \%$ cases were benign and nonneoplastic and $38.7 \%$ were malignant. [8]. Benign lesions is commonly reported in our study similar to Varsha Pandey and Khanna study..

In our study, most common benign lesion diagnosed on cytology was fibroadenoma, 72 cases (69\%). These findings are matching with Varsha Pandey [5], and Pinto [9] whose findings also matched with fibroadenoma as the most common lesion. Out of these 72 cases, smears from one case showed presence of microfilaria in a fibroadenoma which was confirmed on subsequent histopathology (Figure VI a \& VI b).
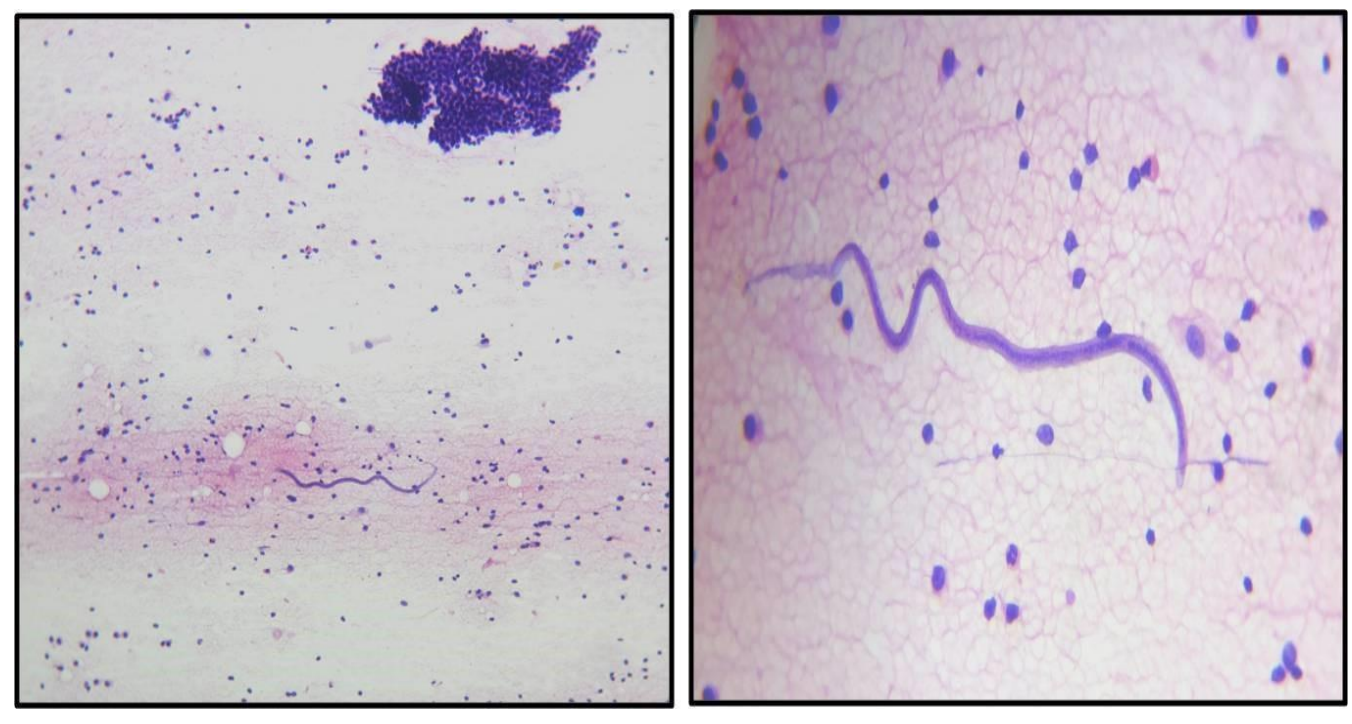

Figure 6a: Fibroadenoma with microfilaria (Cyto: $H \&$ E 10X \& 40X).
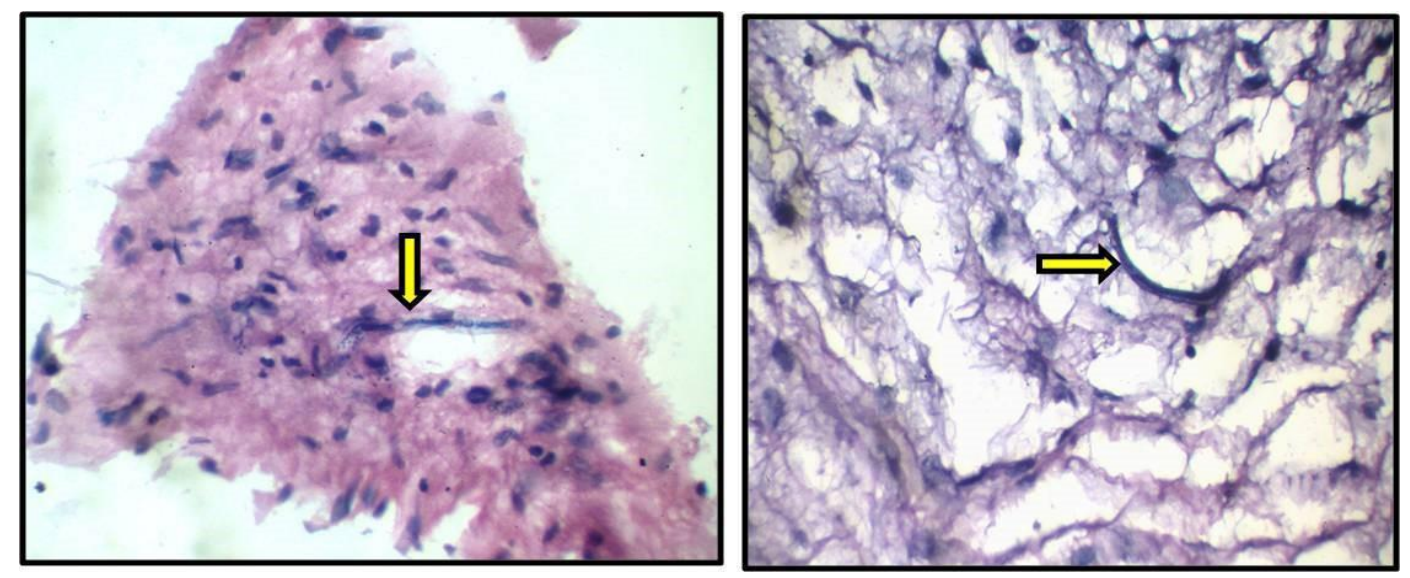

Figure6b: Fibroadenoma with microfilaria (Histo: $H \&$ E 40X). 
This patient was 20 years female hailing from an area where there is endemic for filariasis. Mammary filariasis is not unknown, however microfilaria coexistent with benign neoplasm like fibroadenoma is an unusual association and extremely rare.[10] This was an incidental finding in our case.

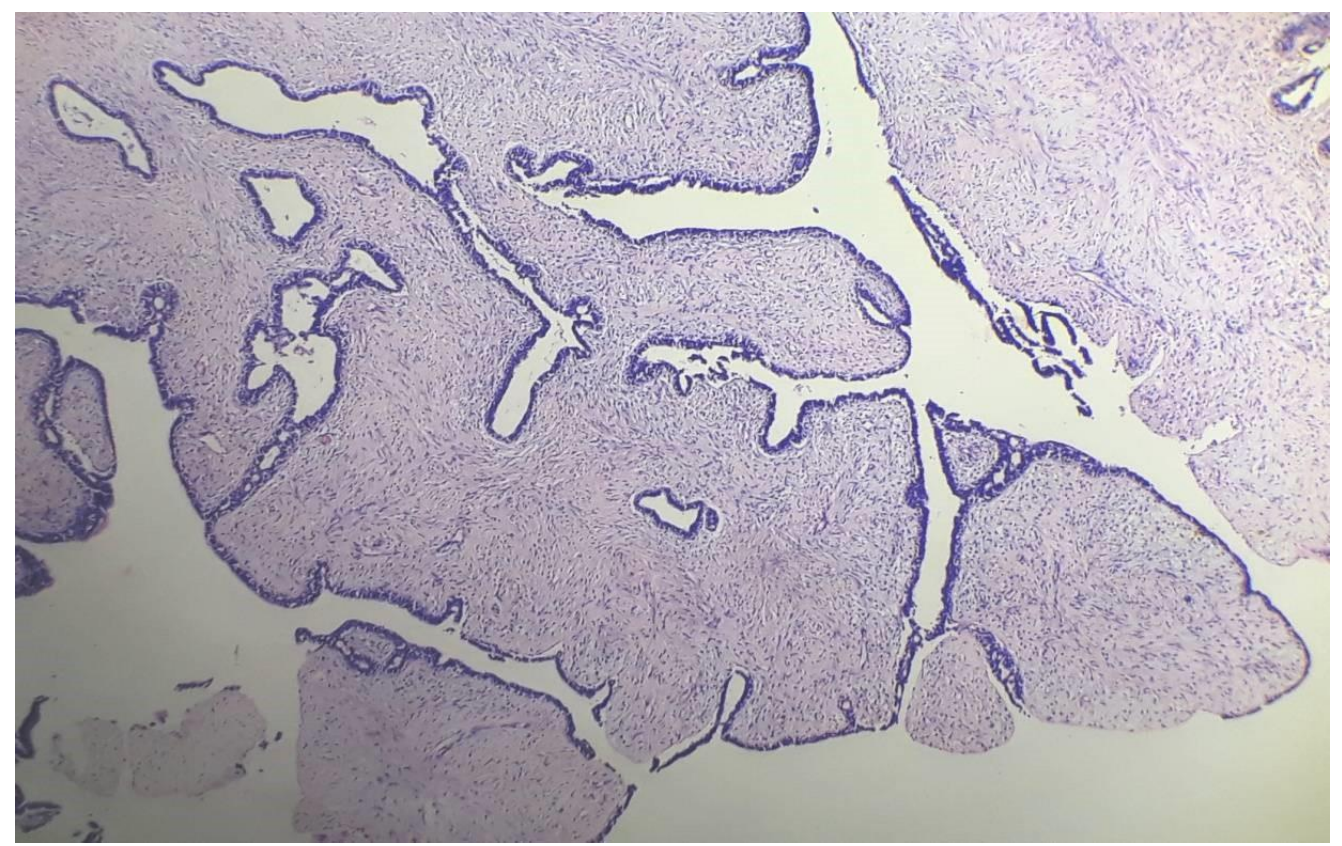

Figure 7: Phyllodes tumour (Histo: $H \&$ E 10X).

Fibroadenoma was confirmed histologically also in 67 / 72 cases, 2 others were reported as phyllodes tumour (Figure VII) and 1 each as intraductal papilloma, duct ectasia and fibroadenoma with atypical ductal hyperplasia.

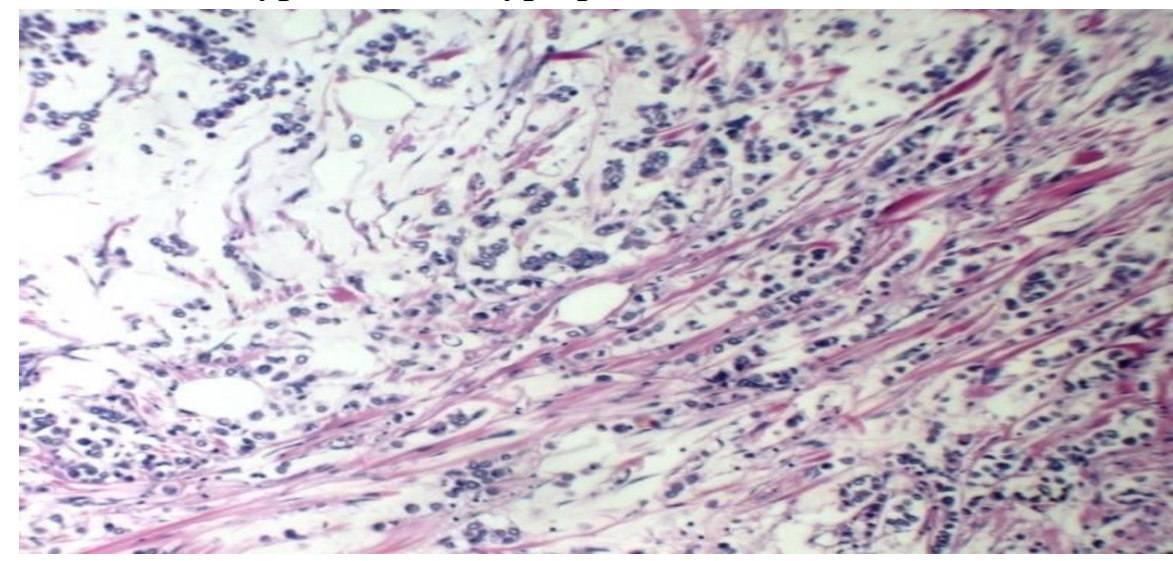

Figure 8a: Invasive lobular carcinoma with extracellular mucin (Histo: $H \&$ E 10X). 


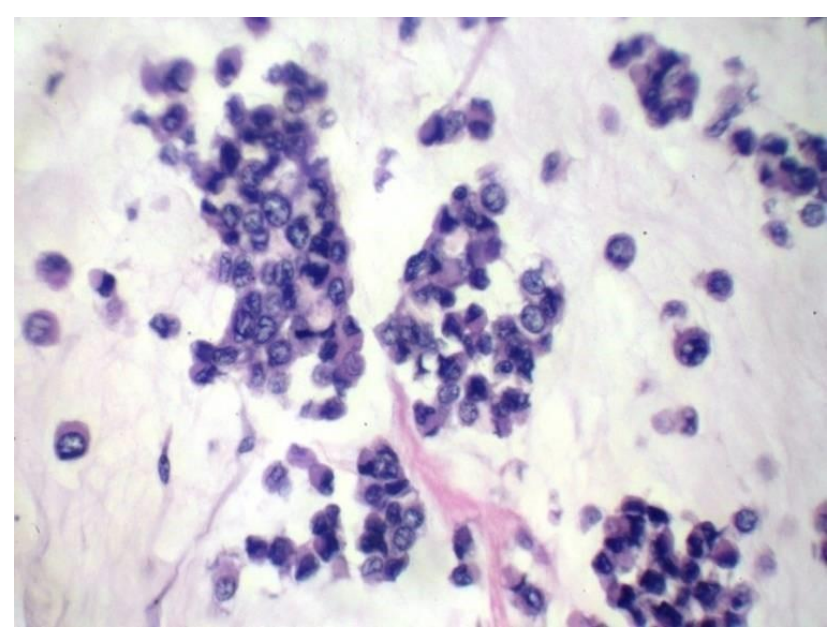

Figure 8b: Invasive lobular carcinoma with extracellular mucin (Histo: $H$ \& E 40 X).
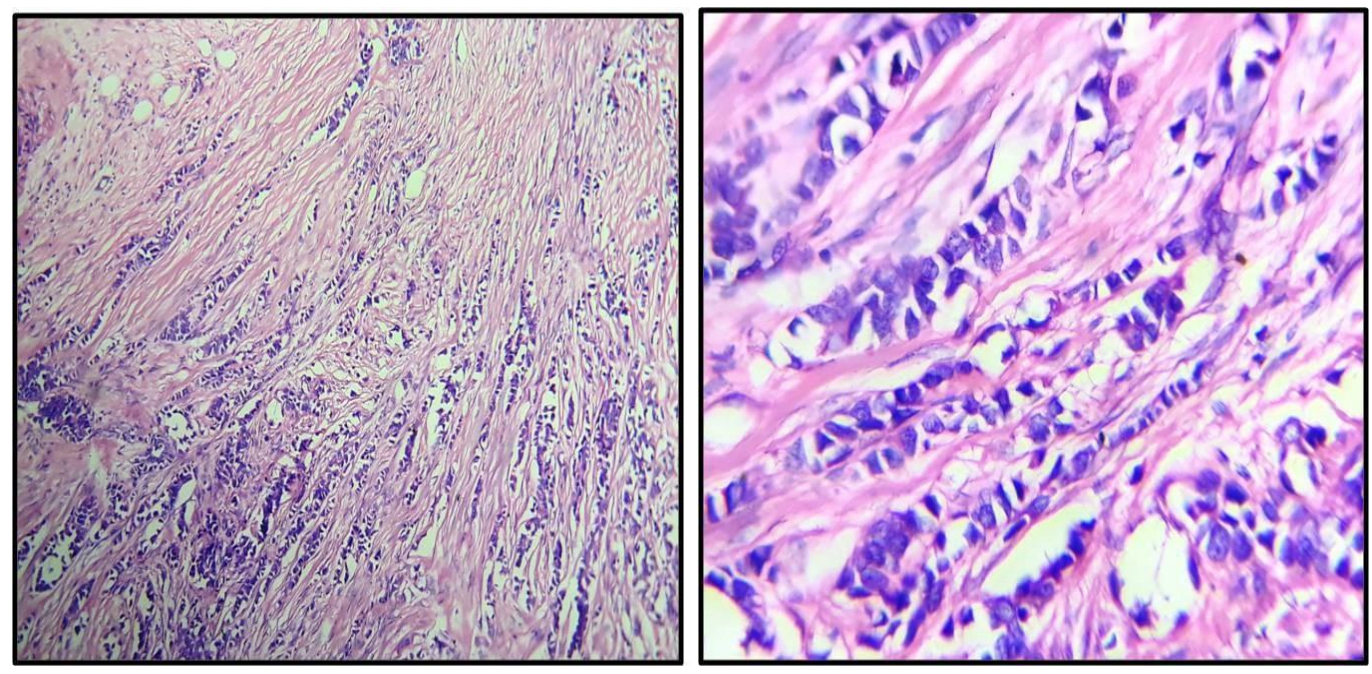

Figure 9: Invasive lobular carcinoma -pleomorphic variant (Histo: $H \& E 10 X \& 40 X$ ).

In Phyllodes tumor, significant epithelial proliferation can be present and occasionally only the epithelial component is represented in smears. In our 2 cases probably, these areas were sampled at FNAC as cytology smears from both the cases showed a predominance of epithelial component. Cytological distinction between fibroadenoma and phyllodes tumor is predominantly based on assessment of cellularity of stromal fragments. In both cases, our smears showed only occasional stromal fragments. This is a diagnostic pitfall in phyllodes tumour $[4,11]$.

Cytology smears in one case of fibroadenoma which was diagnosed as papilloma on histology showed fibroadenoma like cohesive clusters. Papillary fronds, singly scattered 
columnar cells, macrophages or apocrine cells associated with a benign papillary lesion were not seen even on review of the slides.

In one case of fibroadenoma on cytology, histological diagnosis was duct ectasia. Smears in this case were moderately cellular and showed many monolayered sheets and cohesive clusters of ductal cells with single bare nuclei. Foam cells or inflammatory cells were not evident. Cytology smears of duct ectasia are usually paucicellular. Our findings are not consistent with the usual cytological features of duct ectasia.

One case with cytological diagnosis of fibroadenoma showed ductal hyperplasia with nuclear atypia on histopathology which was not represented in cytology smears. The needle probably did not hit the hyperplastic ducts. This patient was advised close follow up. Cyto-histological concurrence was present in 67 of the 72 cases of fibroadenoma (93.05\%). In study by Pinto et al, cyto-histological correlation for fibroadenoma was $89.7 \%$.

In literature it is mentioned that fibrocystic disease, papilloma, phyllodes tumour are grey zone lesions of breast, difficult to classify on FNAC. [12] This is a limitation of FNAC. In another case with histological diagnosis of duct ectasia, aspiration had yielded yellowish white fluid. Cytology smears showed eosinophilic proteinaceous material, occasional clusters of benign ductal cells and few cyst macrophages. Hence a diagnosis of cystic lesion was rendered. In our study, 2 cases each of granulomatous mastitis and fibrocystic disease were confirmed on histopathology also. Sensitivity and Specificity of FNAC in diagnosis of benign lesions was 92.2 $\%$ and $100 \%$ respectively in the present study. This is comparable to studies by Manju Vala [13] and O'Neil [14] who have reported $92 \%$ and $92.17 \%$ sensitivity for benign lesions respectively. In our study, 3 cases were diagnosed as atypical / suspicious lesions on cytology. Biopsy was advised in all cases to rule out or confirm malignancy in view of nuclear atypia cytologically. Histological diagnosis was benign fibroadenoma in one case. In the remaining

2 cases biopsy and subsequent excision revealed infiltrating ductal carcinoma and mucinous carcinoma. Both cases were of low-grade histology. We conclude that all hypercellular smears with nuclear atypia falling short of malignancy should be followed up with biopsy to rule out or confirm malignancy so that further definite management can be planned.

In our study, 24 cases were reported as positive for malignancy on cytology. All were confirmed as malignant on histopathology. Thus FNAC was $100 \%$ sensitive in diagnosis of malignant lesions in our study. Manju Vala ${ }^{13}$ Zhang Qin , ${ }^{15}$ Tiwari ${ }^{16}$ have also reported $100 \%$ sensitivity for diagnosis of malignant lesions in their studies of breast lesions.

The most common malignant lesion on histopathology was infiltrating ductal carcinoma, not otherwise specified (IDC, NOS) (19 cases), followed by infiltrating lobular carcinoma (ILC) (3 cases) and 1 each of mucinous cacinoma and mixed IDC \& ILC. 2 cases of IDC, NOS also showed ductal carcinoma in situ component.

Cyto-histological agreement for ductal carcinoma was present in 19 / 24 cases $(79.2 \%)$. There was lack of cyto-histological agreement in 5 cases which were reported as malignant on histopathology, however they were of non-ductal type. 
In one case of ILC, histopathology sections revealed abundant extracellular mucin. Cytology smears of the same case showed small uniform cells arranged in linear dyscohesive pattern with no apparent mucin. In breast tumors, the presence of extracellular mucin is a feature of ductal tumor. ILC with extracellular mucin is a rare variant, found in our reporting.

2 cases of ILC were of the pleomorphic variant. Cytology smears of these were reviewed and showed clusters and sheets of medium to large cells with nuclear pleomorphism and eosinophilic cytoplasm.

It is not always possible to distinguish between lobular and ductal carcinoma on cytology as some ductal carcinomas of low-grade histology show small relatively uniform tumor cells as in ILC. Conversely cells of lobular carcinoma of the pleomorphic type or alveolar type are larger with larger nuclei as seen in ductal carcinoma NOS.[11]

Histological sections of mucinous carcinoma showed lakes of mucin with nests of tumor cells floating in it. Cytology smears in this case showed only few cells with vacuolated cytoplasm but with no apparent mucinous background.

In the present study, overall statistical analysis revealed a sensitivity of $94.17 \%$, specificity of $100 \%$ and accuracy of $93.26 \%$ in diagnosis of breast lesions. In literature it is mentioned that sensitivity falls in the range of $72 \%$ to $99 \%$ and specificity may be up to $100 \%$.[4, 15, 16, 17] Our results are thus comparable to studies by other authors.

We have also reported very rare cases like association of microfilaria with fibroadenoma on cytology which was confirmed on histopathology and a case of ILC with abundant extracellular mucin on histopathology.

\section{CONCLUSION}

Our conclusion is that FNAC can be used as a reliable method for diagnosis of both benign and malignant breast lesions with higher correlation level of histopathologic findings. It can be used to make decisions about patient management pre-operatively and avoiding unnecessary surgical intervention. In situations, where cytological diagnosis is not clear, preoperative diagnosis can be used to aid surgical biopsy and correlation with ultrasonography and/or mammography findings and clinical examination. Our final conclusion is that FNAC is a reliable and routine preliminary diagnostic procedure which can be used for breast lesion evaluation.

\section{References}

1. Ferlay, J., Soerjomataram, I., Ervik, M., Dikshit, R., Eser, S., Mathers, C. (2012). Cancer Incidence and Mortality Worldwide: IARC Cancer Base No. 11. Lyon, France: International Agency for Research on Cancer. Available from: http://globocan.iarc.fr.

2. Ariga, R., Bloom, K., Reddy, V.B., Kluskens, L., Francescatti, D., Dowlat, K. (2002). Fineneedle aspiration of clinically suspicious palpable breast masses with histopathologic correlation. American Journal of Surgery, 184, 410-3.

3. Tabbara, S.O., Frost, A.R., Stoler, M.H., Sneige. N., Sidawy, M.K. (2000). Changing trends in breast fine needle aspiration: Results of the Papanicolaou Society of Cytopathology Survey. Diagn Cytopathol, 22, 126-30. 
4. Bibbo, M. (1997). Comprehensive Cytopathology ( ${ }^{\text {nd }}$ ed.). Philadelphia: W.B. Saunders Company.

5. Pandey, V., Verma, N.K, Sudarshan V, Chandrakar, K.S., Sharma, A. (2017). Cytohistopathological correlation of breast lesions - A rural hospital based study. Indian Journal of Pathology and Oncology,4(1),117-121.

6. Hussain, M.T. (2015). Comparison of fine needle aspiration cytology with excision biopsy of breast lump. Journal of College of Physicians \& Surgeons Pakistan, 15, 211-4.

7. Yalavarthi, S., Tanikella, R., Prabhala, S., Tallam, U.S. (2014). Histopathological and cytological correlation of tumors of breast. Med J DY Patil Univ,7, 326-331.

8. Khanna, R., Khanna, S., Chaturvedi, S., Arya, N.C. (1998). Spectrum of breast disease in young females; a retrospective study of 1315 patients. Indian Journal of Patholgy Microbiology, 41(4), 397-401.

9. Pinto, R.G., Kulwant, S. (2004). A statistical analysis of fine needle aspiration biopsies in palpable benign (neoplastic and non-neoplastic) breast lesions. Journal of Cytology, 21, 64-7.

10. Pantola, C., Kala, S., Agarwal, A., Khan, L. (2012). Microfilaria in cytological smears at rare sites coexisting with unusual pathology: A series of seven cases. Trop Parasitol, 2, 61-63.

11. Orell, S.R., Sterrett, G.F., Whitaker, D. (2005). Fine Needle Aspiration Cytology (4 ${ }^{\text {th }}$ ed.). New Delhi: Elsevier Publication.

12. Mitra, S., Dey, P. (2015). Grey zone lesions of breast: Potential areas of error in cytology. Journal of Cytology, 32, 145-152.

13. Vala, M.T., Goswami A, Suri SK. Comparative study of cytological and histopathological finding in breast lesion. IOSR Journal of Dental and Medical Sciences. 2014;13(7):05-07.

14. O'Neil, S., Castelli, M., Gattuso, P., Kluskens, L., Madsen, K., Aranha. G. (1997). Fineneedle aspiration of 697 palpable breast lesions with histopathologic correlation. Surgery, 122(4), 824-828.

15. Zhang, Q., Shigui, N., Yuhua, C., Limei, Z. (2004). Fine needle aspiration cytology of Breast Lesions: Analysis of 323 cases. The Chinese-German Journal of Clinical Oncology, 3(3), 172-174.

16. Tiwari, M. (2007). Role of FNAC in diagnosis of breast lumps. Kathmandu University Medical Journal, 5,21 5-217.

17. Mehra, K., Kumar, V., Kaur, R., Gupta, N. (2016). Cyto-histopathological correlation in palpable breast lesions. International Journal of Research in Medical Science, 4(6), 194-194. 